\title{
Cost-Effectiveness of Pazopanib in Advanced Soft Tissue Sarcoma in the United Kingdom
}

\author{
Jordan Amdahl, ${ }^{1}$ Stephanie C. Manson, ${ }^{2}$ Robert Isbell, ${ }^{2}$ Ayman Chit, ${ }^{3,4}$ \\ Jose Diaz, ${ }^{2}$ Lily Lewis, ${ }^{5}$ and Thomas E. Delea ${ }^{1}$ \\ ${ }^{1}$ Policy Analysis Inc. (PAI), Four Davis Court, Brookline, MA 02445, USA \\ ${ }^{2}$ GlaxoSmithKline, Stockley Park West, Uxbridge, Middlesex UB11 1BT, UK \\ ${ }^{3}$ GlaxoSmithKline, 7333 Mississauga Road, Mississauga, ON, Canada L5N 6L4 \\ ${ }^{4}$ University of Toronto, 144 College Street, Toronto, ON, Canada M5S 3M2 \\ ${ }^{5}$ York Health Economics Consortium, Level 2, Market Square, University of York, Heslington, York YO10 5NH, UK
}

Correspondence should be addressed to Thomas E. Delea; tdelea@pai2.com

Received 20 December 2013; Accepted 3 April 2014; Published 12 June 2014

Academic Editor: Antoine Italiano

Copyright (C) 2014 Jordan Amdahl et al. This is an open access article distributed under the Creative Commons Attribution License, which permits unrestricted use, distribution, and reproduction in any medium, provided the original work is properly cited.

In the phase III PALETTE trial, pazopanib improved progression-free survival (PFS) compared with placebo in patients with advanced/metastatic soft tissue sarcomas (mSTS) who had received prior chemotherapy. We used a multistate model to estimate expected PFS, overall survival (OS), lifetime STS treatment costs, and quality-adjusted life-years (QALYs) for patients receiving pazopanib, placebo, trabectedin, ifosfamide, or gemcitabine plus docetaxel as second-line mSTS therapies. The cost-effectiveness of pazopanib was expressed as the incremental costs per QALY gained. Estimates of PFS/OS, adverse events, and utilities for pazopanib and placebo were from the PALETTE trial. Estimates of relative effectiveness of the other comparators were from an unadjusted indirect comparison versus pazopanib. Costs were from published sources. Pazopanib is estimated to increase QALYs by 0.128 and costs by $£ 7,976$ versus placebo; cost per QALY gained with pazopanib versus placebo is estimated to be $£ 62,000$. Compared with the other chemotherapies, pazopanib provides similar QALYs at a lower cost. Pazopanib may not be cost-effective versus placebo but may be cost-effective versus the most commonly used active treatments, although this conclusion is uncertain. Given the unmet need for effective treatments for mSTS, pazopanib may be an appropriate alternative to some currently used medications in the United Kingdom.

\section{Introduction}

Soft tissue sarcomas (STS) are a rare group of solid tumors originating from mesenchymal cells and their precursors. STS includes more than 50 histological subtypes but accounts for less than $1 \%$ of all new malignancies in adults and approximately $2 \%$ of total cancer-related mortality $[1,2]$. In 2010, 3,272 persons in the United Kingdom (UK) were diagnosed with cancer of connective and soft tissue [3].

Surgery, often combined with radiation therapy, offers the only potential cure for localized STS; however, approximately one-half of all patients with STS eventually develop local recurrence or metastases following surgery, radiotherapy, or both $[4,5]$. Advanced STS is typically treated with palliative chemotherapy, and the median overall survival (OS) from the time metastases are found is 14 months [6].

Doxorubicin, alone or combined with ifosfamide, is the standard of care for first-line treatment of STS [5, 7, 8]. Although there is no standard of care following firstline chemotherapy, treatments recommended as second-line therapy by the British Sarcoma Group and the European Society for Medical Oncology are trabectedin, ifosfamide, gemcitabine plus docetaxel, taxanes (including docetaxel), gemcitabine, and dacarbazine $[5,7,8]$. Results from the Sarcoma Treatment and Burden of Illness in North America and Europe (SABINE) trial, a retrospective chart review of patients with metastatic STS, reported that gemcitabine plus docetaxel was the most frequently used second-line 
therapy, followed by ifosfamide monotherapy. Trabectedin was the most frequently used third-line therapy, followed by investigational drugs [9]. Current UK treatment guidelines recommend treatment with trabectedin, gemcitabine, gemcitabine plus docetaxel, or ifosfamide for patients who fail initial chemotherapy with doxorubicin-based therapy $[5,7]$.

Pazopanib (GW786034, Votrient, GlaxoSmithKline, Research Triangle Park, NC, USA), a multiple tyrosine kinase inhibitor, is approved for use in the United States, Canada, and the European Union for the treatment of advanced (unresectable and/or metastatic) STS (aSTS) in patients who have received prior chemotherapy [1012]. Pazopanib was investigated in the PALETTE trial (ClinicalTrials.gov identifier: NCT00753688), a randomized, phase III investigation of pazopanib versus placebo in 369 patients with aSTS who had received prior chemotherapy [12]. Results of the PALETTE trial showed pazopanib improved progression-free survival (PFS) versus placebo (median 4.6 versus 1.6 months, resp.; hazard ratio [HR], 0.35 ; 95\% confidence interval $[\mathrm{CI}], 0.26-0.48 ; P<0.001$ ) [10]. Median OS, a secondary objective of the trial, was 12.6 versus 10.7 months, respectively ( $\mathrm{HR}, 0.87 ; 95 \% \mathrm{CI}$, 0.67-1.12; $P=0.26$ ) [10]. However, posttreatment anticancer therapy (PTACT) was received by $62 \%$ in the placebo group compared with $45 \%$ in the pazopanib group at the data cutoff date [12], which may have diluted the survival benefit of pazopanib. Patients in the pazopanib arm were more likely to experience at least one on-therapy adverse event (AE) (99\% versus $89 \%$ ) and at least one serious AE (SAE) (41\% versus 24\%) compared with patients in the placebo arm [13]. The most frequently reported on-treatment AEs in the pazopanib group included fatigue, diarrhea, nausea, decreased weight, hypertension, and decreased appetite.

The primary objective of this study was to evaluate the cost-effectiveness of pazopanib versus best supportive care (BSC) from a UK healthcare system perspective when used in patients with aSTS who have received prior anthracyclinebased chemotherapy.

\section{Methods}

2.1. Model Description. A multistate model was used to estimate expected PFS, OS, lifetime costs of treatment of aSTS, and quality-adjusted life-years (QALYs) in patients who had received prior treatment with chemotherapy and who were assumed to receive pazopanib, placebo, or chemotherapy. The model was developed in Microsoft Excel (Microsoft Corporation, Redmond, WA, USA).

Consistent with the modeling approach used in a multitude of other evaluations of treatments for advanced oncology indications [14-16], patients in the model were assumed to be in one of three mutually exclusive heath states at any given time: alive with no progression (PFS), alive with disease progression (postprogression survival [PPS]), or dead. The model was designed to permit two alternative approaches to estimate the proportion of patients in each health state over time. With the "partitioned-survival analysis" approach, survival distributions for PFS and OS were entered into the model, and the proportion of patients in the PPS state was calculated as the difference between OS and PFS. Alternatively, with the "Markov cohort analysis" approach, survival distributions for PFS and PPS were entered into the model, along with the estimated proportion of PFS events that are deaths. Transition probabilities were then derived from these inputs and combined to calculate the survival distribution for OS. With both approaches, expected costs and QALYs for each strategy were calculated as the product of the expected PFS and PPS and corresponding cost and utility value estimates for pre- and postprogression survival time, adjusted for "one-off" decrements in costs and quality of life associated with treatment initiation, AEs, progression, and death.

Expected lifetime outcomes and costs were evaluated over a 10-year timeframe, approximating a lifetime projection for patients with aSTS (i.e., virtually all patients were projected to be dead after 10 years). The model periodicity (i.e., the minimum duration of time a patient might remain in any disease state) was one week. Effectiveness measures were calculated on a discounted and undiscounted basis; costs were calculated on a discounted basis only. A 3.5\% annual discount rate was employed beginning at the end of the first year of the model [17]. A UK healthcare system perspective was employed.

The primary analysis focused on direct comparisons of pazopanib versus BSC. In this analysis, data on PFS and OS for placebo patients from PALETTE were used without any adjustment of OS for the differential receipt of PTACT in the two groups. Utilization (and therefore costs) of PTACT was assumed to differ between groups as observed in PALETTE. For this analysis, the partitioned-survival analysis modeling approach was employed (i.e., the model took as inputs the distribution of OS rather than the distribution of PPS).

In a secondary analysis, pazopanib was compared with trabectedin $\left(1.5 \mathrm{mg} / \mathrm{m}^{2}\right)$, ifosfamide $\left(3 \mathrm{~g} / \mathrm{m}^{2}\right)$, and gemcitabine plus docetaxel $\left(900 \mathrm{mg} / \mathrm{m}^{2}, 100 \mathrm{mg} / \mathrm{m}^{2}\right)$. These therapies were the most relevant chemotherapy comparators in the UK based on treatment patterns reported in the SABINE study and consultation with clinical experts. In this analysis, a Markov cohort approach was employed, and it was assumed that PPS and PTACT utilization and costs would be the same for chemotherapy and pazopanib. Because PPS was assumed to be the same for pazopanib and chemotherapy, the difference between treatment strategies in mean OS was assumed to be equal to the difference in PFS (i.e., the benefits in PFS for pazopanib were assumed to translate directly to benefits of equal magnitude in OS). This approach was used because there was insufficient data from controlled trials to conduct robust adjusted indirect treatment comparisons of PFS and OS [18]. Accordingly, these comparisons were based on naive or unadjusted indirect comparisons. Because data on OS is more likely to be impacted by differences in patient populations and trial design than data on PFS, it was believed that the comparisons would be more reliable if based on PFS alone rather than PFS and OS. Also, there is no reason to believe that PPS would be different for patients receiving pazopanib versus chemotherapy. 
TABLE 1: Survival distribution inputs.

\begin{tabular}{|c|c|c|c|}
\hline & Pazopanib & Placebo & Reference \\
\hline \multicolumn{4}{|l|}{ Weibull survival function parameters } \\
\hline \multicolumn{4}{|l|}{ PFS (months) } \\
\hline Lambda & 0.1279 & 0.3714 & PALETTE \\
\hline Gamma & 1.1252 & 1.0809 & PALETTE \\
\hline \multicolumn{4}{|l|}{ OS (months) } \\
\hline Lambda & 0.0282 & 0.0469 & PALETTE \\
\hline Gamma & 1.2341 & 1.1027 & PALETTE \\
\hline \multicolumn{4}{|l|}{ PPS (months) } \\
\hline Lambda & 0.104 & 0.118 & PALETTE \\
\hline Gamma & 0.902 & 0.898 & PALETTE \\
\hline $\begin{array}{l}\text { Probability of death without disease progression } \\
\text { (required for Markov cohort model) }^{\mathrm{a}}\end{array}$ & 0.053 & 0 & PALETTE \\
\hline \multicolumn{4}{|l|}{ HR for PFS for pazopanib versus comparator } \\
\hline Ifosfamide & \multicolumn{2}{|c|}{$0.91(95 \%$ CI, 0.73-1.14) } & $\begin{array}{c}\text { Sharma et al. } 2013 \text { [18] } \\
\text { van Oosterom et al. } 2002 \text { [43] }\end{array}$ \\
\hline Trabectedin & \multicolumn{2}{|c|}{0.90 (95\% CI, 0.76-1.07) } & $\begin{array}{c}\text { Sharma et al. } 2013 \text { [18] } \\
\text { Demetri et al. } 2009 \text { [44] } \\
\text { Garcia-Carbonero et al. } 2005 \text { [45] } \\
\text { le Cesne et al. } 2005[46] \\
\text { Yovine et al. } 2004 \text { [47] }\end{array}$ \\
\hline Gemcitabine + docetaxel & \multicolumn{2}{|c|}{$0.99(95 \%$ CI, $0.70-1.40)$} & $\begin{array}{c}\text { Sharma et al. } 2013 \text { [18] } \\
\text { Hensley et al. } 2008 \text { [48] } \\
\text { Pautier et al. } 2012 \text { [33] }\end{array}$ \\
\hline
\end{tabular}

CI: confidence interval; HR: hazard ratio; OS: overall survival; PFS: progression-free survival; PPS: postprogression survival.

${ }^{a}$ Same value was assumed for chemotherapies in indirect comparison.

2.2. Model Estimation. A summary of model inputs can be found in Table 1. PFS, OS, and PPS were estimated for pazopanib and placebo by fitting parametric survival functions to patient-level data from PALETTE using accelerated failure time regression (Figure 1) [19]. Investigatorassessed PFS (including clinical progression) was used as it was considered most likely to reflect PFS in clinical practice. OS was based on intent-to-treat analyses. Survival distributions for pazopanib and placebo were estimated independently. Exponential, Weibull, and log-logistic models were considered. Based on visual inspection and comparison of the restricted mean (i.e., area under the curve) for the empirical versus fitted distributions, the Weibull distribution provided the best fit for all distributions and was used in base-case analyses. Because the OS distribution for pazopanib derived from the PFS and PPS distributions in the Markov cohort analysis approach did not match the tail end of the empirical OS distribution well, the parameters of the PPS Weibull distribution were adjusted by calibrating the parameters of the distribution to minimize the differences between the model projections of expected OS and those obtained from the Weibull distribution fit to OS directly.

PFS for the other comparators was estimated by applying to the estimated PFS distribution for pazopanib estimates of the HRs for these treatments versus pazopanib using the formula

$$
\operatorname{PFS}_{\text {Comparator }}[t]=\operatorname{PFS}_{\text {Pazopanib }}[t]^{\mathrm{HR}_{\text {Comparator versus Pazopanib }}} \text {. }
$$

HRs for PFS for each comparator versus pazopanib were estimated using data from published studies of the comparators of interest that were identified based on a systematic review of the literature (Table 2). HRs were calculated by comparing the published Kaplan-Meier curves for PFS (or time to progression if PFS was unavailable) for the comparator(s) of interest in each study with the Kaplan-Meier PFS curve for pazopanib from PALETTE [20].

In PALETTE, the EuroQol 5-dimension (EQ-5D) health questionnaire was assessed only at baseline and at 4 weeks, whereas the European Organization for Research and Treatment of Cancer Quality of Life Questionnaire (EORTC QLQC30) was also assessed at 8 and 12 weeks $[12,13]$. Therefore, a mapping algorithm was developed using data for the EQ5D and QLQ-C30 at baseline and four weeks to predict EQ$5 \mathrm{D}$ utility values at 8 and 12 weeks given the responses to the EORTC QLQ-C30 at those later assessments [21]. The observed and mapped utility values were then combined to calculate mean utility values for each group for all preand postprogression assessments. Because the mean time from progression to postprogression utility assessment in PALETTE was only approximately one week in both groups, the mean differences in utility post- versus preprogression from PALETTE reflect declines in utility values immediately following progression only and do not reflect the declines in utility that would be expected over the entire postprogression period [22-25]. Accordingly, postprogression utility values for pazopanib and placebo were obtained by combining 


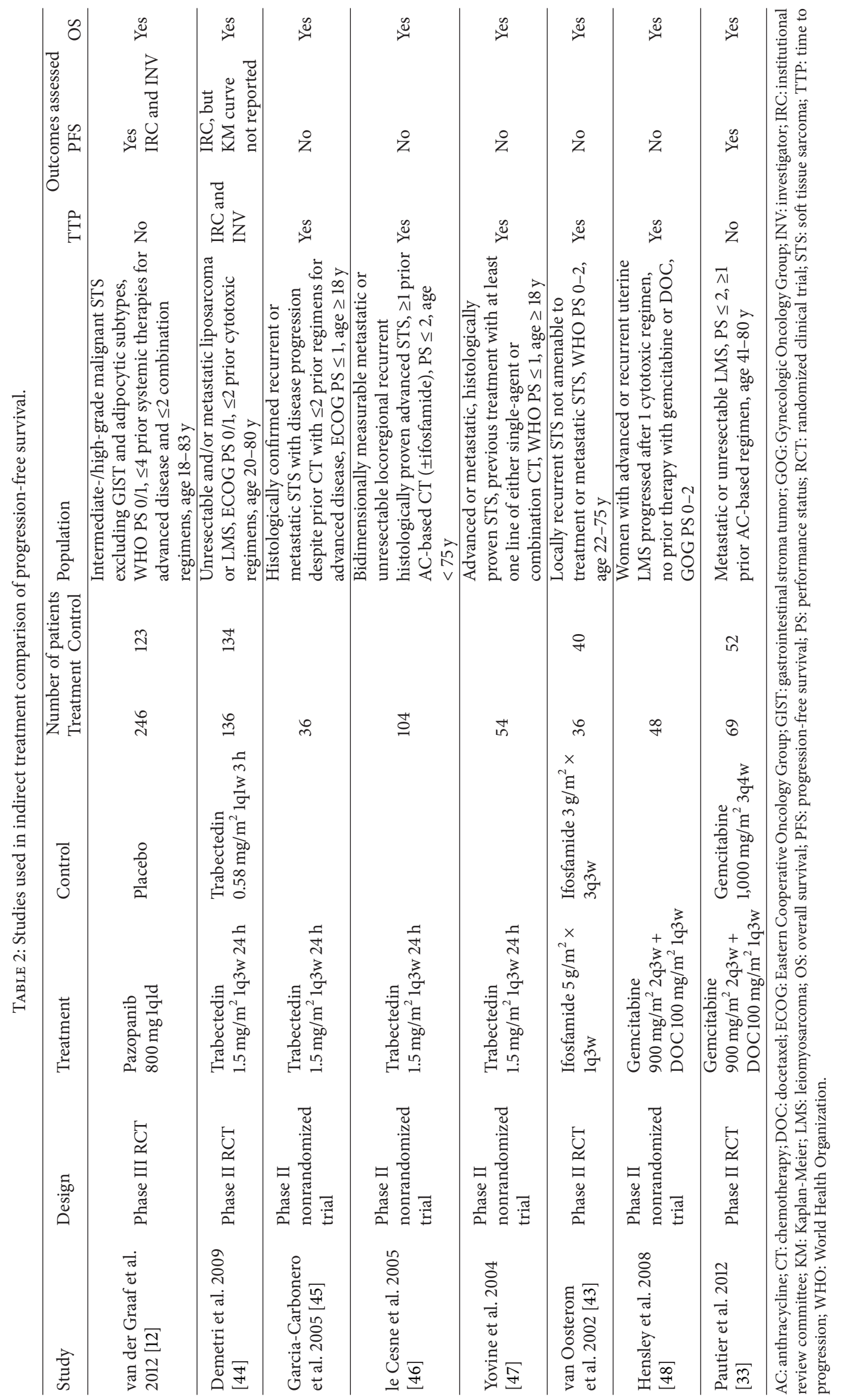


TABLE 3: Utility values used in the model.

\begin{tabular}{|c|c|c|}
\hline & Mean (SE) & Source \\
\hline \multicolumn{3}{|l|}{ Utility values for PFS and PPS, mean (SE) } \\
\hline \multicolumn{3}{|l|}{ Preprogression } \\
\hline Pazopanib & $0.674(0.015)$ & PALETTE \\
\hline Placebo & $0.678(0.024)$ & PALETTE \\
\hline \multicolumn{3}{|l|}{ Postprogression } \\
\hline Pazopanib & $0.568(0.044)$ & PALETTE \\
\hline Placebo & $0.636(0.040)$ & PALETTE \\
\hline \multicolumn{3}{|l|}{ Estimated disutility values for AEs (SE) } \\
\hline Alopecia & $0.045(0.015)$ & Nafees et al. 2008 [27] \\
\hline Anemia/hemoglobin & $0.119(0.023)$ & Swinburn et al. 2010 [28] \\
\hline Asthenia/fatigue & $0.262(0.027)$ & Shingler et al. 2013 [26] \\
\hline Cardiovascular (cardiac toxicity/left ventricular dysfunction) & $0.2(0)$ & Assumption \\
\hline Decreased appetite/anorexia/weight decreased & $0.2(0)$ & Assumption \\
\hline Diarrhea & $0.327(0.028)$ & Shingler et al. 2013 [26] \\
\hline Edema & $0.2(0)$ & Assumption \\
\hline Febrile neutropenia & $0.09(0.016)$ & Nafees et al. 2008 [27] \\
\hline Leucopoenia/neutropenia/neutrophils/thrombocytopenia/low platelets & $0.09(0.015)$ & Nafees et al. 2008 [27] \\
\hline Liver toxicity (ALT/AST elevation) & 0 & Assumption \\
\hline Hypertension & $0.153(0.024)$ & Swinburn et al. 2010 [28] \\
\hline Myalgia/muscle pain/neurotoxicity/peripheral sensory neuropathy & $0.236(0.025)$ & Shingler et al. 2013 [26] \\
\hline Nausea/vomiting & $0.357(0.026)$ & Shingler et al. 2013 [26] \\
\hline Pulmonary (dyspnea/pleural effusion/pneumothorax/pulmonary toxicity) & $0.242(0.026)$ & Shingler et al. 2013 [26] \\
\hline
\end{tabular}

AEs: adverse events; ALT: alanine aminotransferase; AST: aspartate aminotransferase; HR: hazard ratio; OS: overall survival; PFS: progression-free survival; PPS: postprogression survival; SE: standard error.

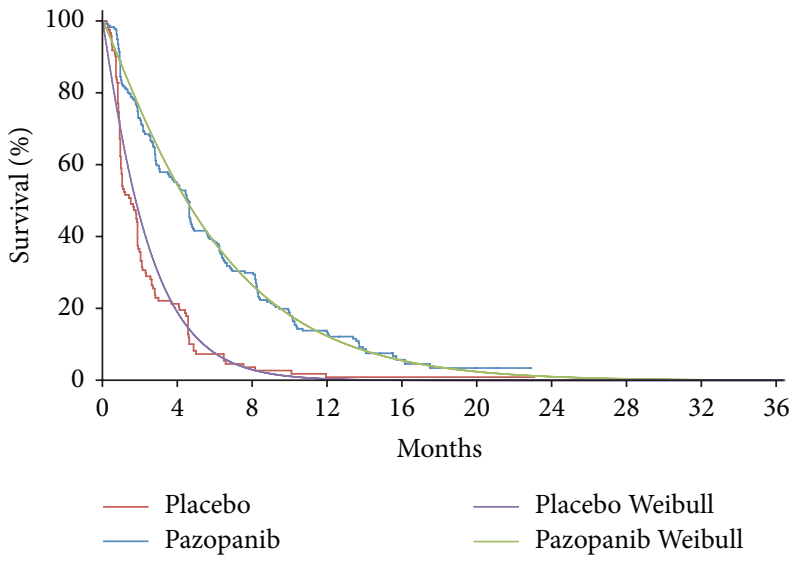

(a)

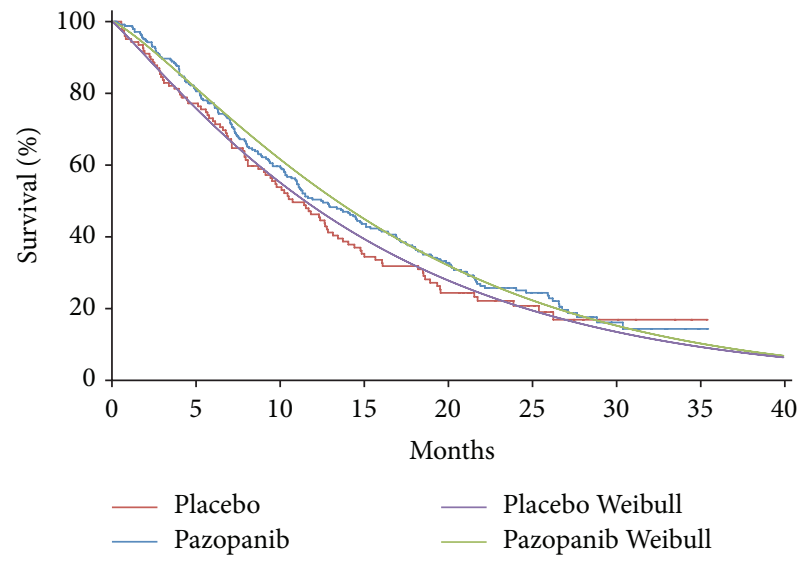

(b)

FIGURE 1: Weibull versus Kaplan-Meier survival distributions for (a) progression-free survival and (b) overall survival of pazopanib and placebo for patients in the PALETTE trial.

treatment group-specific estimates of the mean decrement in utility postprogression in PALETTE (reflecting the period immediately following progression) with an estimate of utility in the terminal phase of the disease. The latter was based on the estimated utility value for progressive disease from a vignettes study by Shingler and colleagues (mean [standard error], 0.263 [0.0231]) [26]. For the comparisons of pazopanib with chemotherapies, QALYs were adjusted for differences between treatments in the incidence of AEs using data on the incidence of AEs from PALETTE and the studies of chemotherapies noted above as well as disutility values for AEs that were obtained from published vignettes studies [26-28]. Utility values used in the model are reported in Table 3. 
TABLE 4: Cost estimates used in the model.

\begin{tabular}{lcc}
\hline Estimate & Costs, $£$ & Reference \\
\hline $\begin{array}{l}\text { Medications unit costs } \\
\text { Pazopanib, 200 mg tablet } \\
\text { (no discount) }\end{array}$ & 18.68 & $\begin{array}{c}\text { British National } \\
\text { Formulary [32] }\end{array}$ \\
$\begin{array}{l}\text { Pazopanib, 200 mg tablet } \\
\text { (with discount) }\end{array}$ & 16.35 & \\
Trabectedin (per mg) & 1,366 & \\
Ifosfamide (per mg) & 0.04 & \\
Gemcitabine (per mg) & 0.14 & \\
Docetaxel (per mg) & 5.14 & \\
Lenograstim (per mg) & 238 & \\
Mesna (per mg) & 0.010 & \\
\hline
\end{tabular}

Total costs of poststudy chemotherapy

\begin{tabular}{lcc} 
Placebo & 11,493 & $\begin{array}{c}\text { PALETTE, British } \\
\text { National Formulary [32] }\end{array}$ \\
\hline Pazopanib $^{\mathrm{b}}$ & 8,531 & $\begin{array}{c}\text { NHS 2010-2011 } \\
\text { Reference Costs [35] }\end{array}$ \\
\hline Administration/dispensing $^{\text {Pazopanib }}$ & 12.00 & $\begin{array}{c}\text { NHS 2010-2011 } \\
\text { Reference Costs [35] }\end{array}$ \\
$\begin{array}{l}\text { Ifosfamide } \\
\text { Trabectedin }\end{array}$ & 331.49 & \\
$\begin{array}{l}\text { Gemcitabine plus docetaxel } \\
\text { Management costs }\end{array}$ & 331.49 & \\
$\begin{array}{l}\text { Preprogression monthly } \\
\text { cost }\end{array}$ & 92.68 & Judson et al. 2007 [36] \\
$\begin{array}{l}\text { Postprogression monthly } \\
\text { cost }\end{array}$ & 185 & \\
\hline
\end{tabular}

${ }^{\mathrm{a}}$ Costs are capped after five cycles; ${ }^{\mathrm{b}}$ poststudy costs are assumed to be the same for pazopanib, ifosfamide, trabectedin, and gemcitabine + docetaxel in the indirect comparison; ${ }^{c}$ costs are updated to $2010 / 11$ prices; preprogression costs are assumed to be half of postprogression costs.

In the model, patients receiving pazopanib were assumed to incur the cost of a 28-day supply of pazopanib each 28day cycle if they remained alive and progression-free. Any medication supplied but not taken was assumed to be discarded. Drug utilization was adjusted for dosage adjustment, early discontinuation, and interruptions. It was assumed that pazopanib would be provided to the UK National Health Service (NHS) at a $12.5 \%$ discount to the list price consistent with a published patient access scheme (PAS) agreement between the NHS and GlaxoSmithKline [29]. The cost of trabectedin medication was calculated assuming that the acquisition cost of trabectedin to the NHS would be capped at five cycles of treatment, consistent with a PAS agreement between the manufacturer of trabectedin (PharmaMar, Colmenar Viejo, Spain) and the NHS [30]. However, administration costs after five cycles were included in the cost estimate.

Expected costs of PTACT for each treatment group were calculated by combining Kaplan-Meier sample average estimates of the mean number of lines of PTACT received and treatment group-specific estimates of the distribution of
PTACTs in PALETTE with corresponding estimates of the cost per course of each PTACT (for details, see Table 7) [31]. The mean duration of PTACT was assumed to be 4 months, which was an average of the mean PFS in the placebo and pazopanib arms in PALETTE (2.5 and 6 months, resp.). This value is similar to the mean time between lines of PTACT for patients who received more than one PTACT in PALETTE (4.5 months). Dosages for PTACTs were based on published studies and prescribing information.

Medication unit costs were obtained from the 63rd edition of the British National Formulary (details on drug and administration costs are listed in Table 4) [32]. Patients treated with ifosfamide were assumed to receive concomitant treatment with mesna to prevent urotoxicity. Patients receiving gemcitabine plus docetaxel were assumed to receive treatment with lenograstim to prevent neutropenic complications; those with prior pelvic irradiation were assumed to receive a $25 \%$ dose reduction of gemcitabine plus docetaxel [33]. Administration costs included the cost of dispensing pazopanib based on the hourly cost of a hospital pharmacist (as reported by Personal Social Services Research Unit) [34] and assumed each dispensation requires 15 minutes. Facility costs for administering trabectedin and ifosfamide were based on a weighted average of the outpatient and day case 2010/2011 NHS reference costs for HRG SB14Z, “delivery of complex chemotherapy (including prolonged infusional treatment at first attendance)" [35].

The costs of treatment of AEs were calculated by multiplying estimates of the incidence of AEs with estimates of the cost of treatment for each event (Table 8 ). Only grade 3-5 AEs for which the difference in incidence between pazopanib and placebo was $\geq 2 \%$ or that were considered by clinical experts to be of special interest were considered. Estimates of the incidence of AEs for pazopanib and placebo were from the PALETTE trial. Estimates of the incidence of AEs for chemotherapies were based on reported values in the literature. In the absence of a reported value, AE incidence was assumed to be equal to the AE incidence in the placebo arm of the PALETTE trial. All AEs were assumed to require one additional consultant visit, the cost of which was based on the NHS reference costs for HRG 800 "Clinical Oncology, Consultant Led: Follow up Attendance Non-Admitted Face to Face" [35]. The proportions of patients requiring hospitalization for each AE were estimated separately for pazopanib and placebo and were based on the proportions of events that were serious in each arm of PALETTE. Lacking similar data for trabectedin, ifosfamide, and gemcitabine plus docetaxel, the proportions of events resulting in hospitalization for these therapies were assumed to be the same as those for pazopanib. The costs of hospitalizations for AEs were based on 2010/11 NHS reference costs for nonelective inpatient stays for these events (long stay and short stay) [35] (Table 9).

Other STS-related direct medical costs were estimated based on a retrospective study of the cost of the management of metastatic STS in the UK by Judson and colleagues [36].

2.3. Sensitivity Analyses. Deterministic and probabilistic sensitivity analyses were undertaken to explore the effect of 


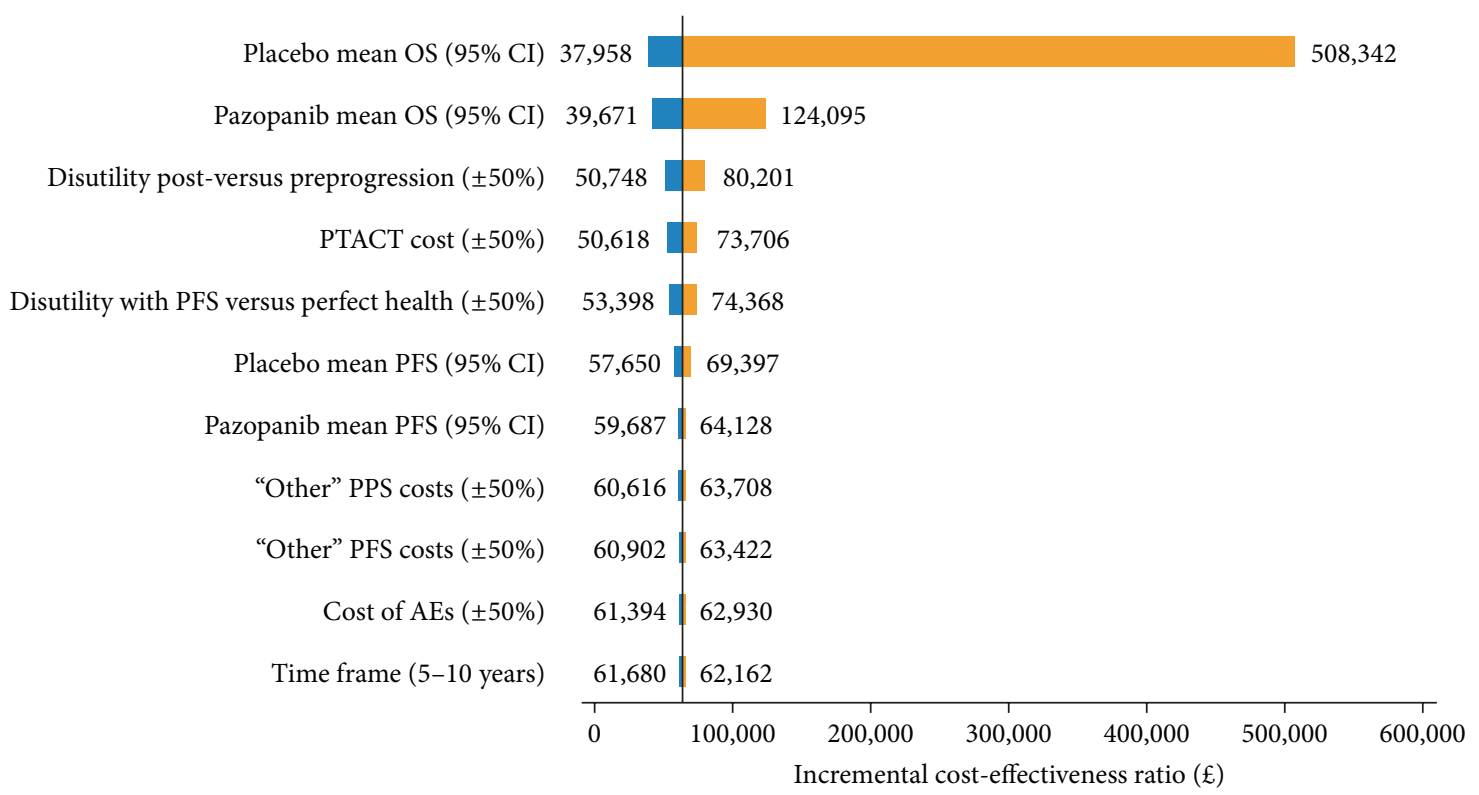

FIGURE 2: Tornado diagram showing result of deterministic sensitivity analysis for the direct comparison of cost-effectiveness of pazopanib versus placebo. Parameters were varied by 0.5 or 1.5 and shown on either side of the graph. AE: adverse events; CI: confidence interval; OS: overall survival; PFS: progression-free survival; PPS: postprogression survival; PTACT: posttreatment anticancer therapy.

TABLE 5: Base-case results for direct comparison of costeffectiveness of pazopanib versus placebo.

\begin{tabular}{lccc}
\hline & Pazopanib Placebo & $\begin{array}{c}\text { Pazopanib versus } \\
\text { placebo }\end{array}$ \\
\hline Effectiveness (discounted) & & & \\
$\quad$ LYs & 1.375 & 1.262 & 0.113 \\
PFLYs & 0.503 & 0.211 & 0.292 \\
PPLYs & 0.872 & 1.051 & -0.179 \\
QALYs & 0.719 & 0.591 & 0.128 \\
Costs (discounted), & & & \\
Study medication & 10,733 & 0 & 10,733 \\
Administration & 81 & 0 & 81 \\
Adverse events & 251 & 54 & 197 \\
Other costs PFS & 557 & 234 & 323 \\
Other costs PPS & 10,463 & 13,822 & $-3,359$ \\
Total & $\mathbf{2 2 , 0 8 6}$ & $\mathbf{1 4 , 1 1 0}$ & $\mathbf{7 , 9 7 6}$ \\
\hline Cost per QALY gained & & & 62,162 \\
\hline
\end{tabular}

LYs: life-years; PFLYs: progression-free life-years; PFS: progression-free survival; PPLYs: postprogression life-years; PPS: postprogression survival; QALYs: quality-adjusted life-years.

changing assumptions concerning key model parameter values on model results and cost-effectiveness acceptability curves generated $[37,38]$.

\section{Results}

3.1. Direct Comparison. In the base-case analyses (Table 5), pazopanib was estimated to increase QALYs by 0.128 and costs by $£ 7,976$ compared with placebo. The incremental costeffectiveness ratio (ICER) of pazopanib versus placebo was estimated to be $£ 62,162$ per QALY gained.

Results for the deterministic sensitivity analysis are presented in Figure 2. In this analysis, the most influential variables were mean OS in the placebo group (range: $£ 37,958$ $£ 508,342$ ) and mean OS in the pazopanib group (range: $£ 39,671-£ 124,095)$. For most parameters, the ICER changed $<30 \%$ with $\pm 50 \%$ changes in the parameter value.

Probabilistic sensitivity analysis and acceptability curves for the comparison of pazopanib and placebo are presented in Figures 3(a) and 3(b), respectively. A high concentration of simulations was present in the north-eastern quadrant of the cost-effectiveness plane. Given a threshold value of $£ 30,000$ per QALY gained, there is an estimated $2.2 \%$ probability that pazopanib is preferred (i.e., considered to be cost-effective) versus placebo.

3.2. Indirect Comparisons. Results for comparisons of pazopanib versus ifosfamide, trabectedin, and gemcitabine plus docetaxel are summarized in Table 6. Pazopanib was estimated to gain $0.040,0.029$, and 0.001 QALYs versus ifosfamide, trabectedin, and gemcitabine plus docetaxel, respectively. Pazopanib was less costly than ifosfamide ( $£ 3,957$ savings), trabectedin ( $£ 6,729$ savings), and gemcitabine plus docetaxel ( $£ 2,692$ savings). These results suggest pazopanib is dominant (i.e., lower costs and greater QALYs) compared with each comparator. In probabilistic sensitivity analyses, there was an estimated $100 \%$ probability that pazopanib is cost-effective versus ifosfamide or trabectedin and $98 \%$ probability versus gemcitabine plus docetaxel. 
TABLE 6: Base-case results for pairwise indirect comparisons versus pazopanib (PPS-based analysis).

\begin{tabular}{|c|c|c|c|c|c|c|c|}
\hline & Pazopanib $^{\mathrm{a}}$ & Trabectedin & Ifosfamide & $\begin{array}{l}\text { Gemcitabine } \\
\text { + docetaxel }\end{array}$ & $\begin{array}{l}\text { Pazopanib } \\
\text { versus } \\
\text { trabectedin } \\
\end{array}$ & $\begin{array}{l}\text { Pazopanib } \\
\text { versus } \\
\text { ifosfamide } \\
\end{array}$ & $\begin{array}{c}\text { Pazopanib versus } \\
\text { gemcitabine } \\
+ \text { docetaxel }\end{array}$ \\
\hline \multicolumn{8}{|c|}{ Effectiveness (discounted) } \\
\hline LYs & 1.375 & 1.334 & 1.336 & 1.373 & 0.041 & 0.039 & 0.003 \\
\hline PFLYs & 0.503 & 0.461 & 0.463 & 0.500 & 0.042 & 0.040 & 0.003 \\
\hline PPLYs & 0.872 & 0.874 & 0.873 & 0.872 & -0.001 & -0.001 & 0.000 \\
\hline QALYs & 0.692 & 0.663 & 0.652 & 0.691 & 0.029 & 0.040 & 0.001 \\
\hline \multicolumn{8}{|l|}{ Costs (discounted), $£$} \\
\hline Study medication & 10,733 & 11,699 & 5,675 & 9,769 & -965 & 5,059 & 964 \\
\hline Administration & 81 & 2,491 & 6,516 & 2,707 & $-2,411$ & $-6,435$ & $-2,627$ \\
\hline Adverse events & 653 & 3,481 & 2,706 & 1,685 & $-2,828$ & $-2,053$ & $-1,033$ \\
\hline Other costs PFS & 557 & 1,080 & 1,082 & 554 & -522 & -525 & 3 \\
\hline Other costs PPS & 10,464 & 10,466 & 10,466 & 10,464 & -3 & -3 & 0 \\
\hline Total & 22,488 & 29,217 & 26,445 & 25,180 & $-6,729$ & $-3,957$ & $-2,692$ \\
\hline Cost per QALY gained & & & & & Dominant & Dominant & Dominant \\
\hline
\end{tabular}

LYs: life-years; PFLYs: progression-free life-years; PFS: progression-free survival; PPLYs: postprogression life-years; PPS: postprogression survival; QALYs: quality-adjusted life-years.

${ }^{a}$ Because a Markov methodology was used for the indirect comparison, the effectiveness and cost results are similar but not identical to the direct comparison with placebo.

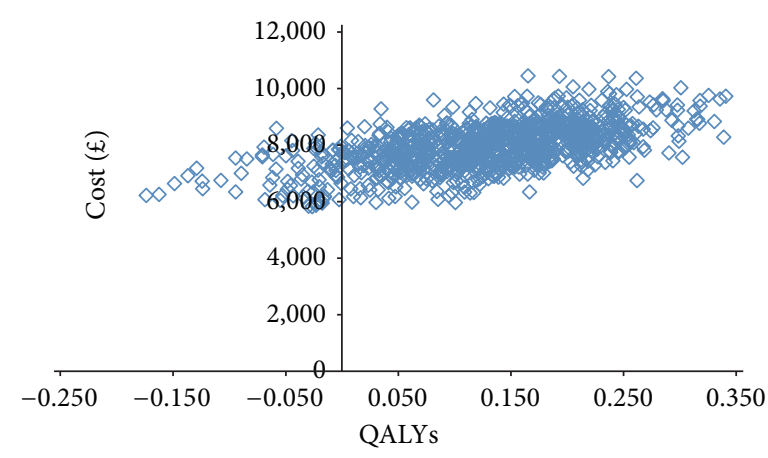

(a)

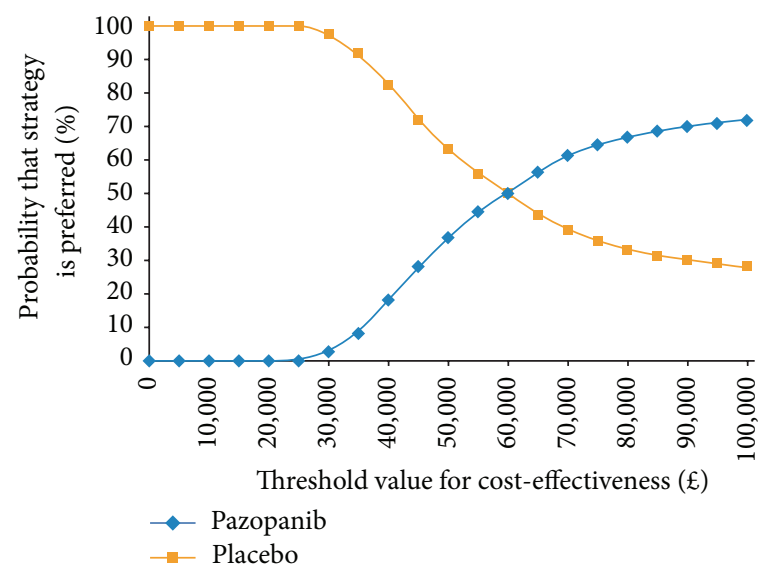

(b)

FIgURE 3: (a) Probabilistic sensitivity analyses for comparison of cost-effectiveness of pazopanib versus placebo. (b) Acceptability curve for comparison of cost-effectiveness of pazopanib versus placebo. QALYs: quality-adjusted life-years.

\section{Discussion}

This study was a cost-effectiveness evaluation of pazopanib in the treatment of patients with aSTS who have received prior chemotherapy from the perspective of the UK healthcare system. The primary analysis focused on a comparison of pazopanib and placebo. Based on cost-effectiveness criteria used by the National Institute for Health and Care Excellence (NICE), the results of our analysis suggest pazopanib is not cost-effective compared with placebo or BSC in these patients from a UK healthcare system perspective [39]. However, pazopanib might be cost-effective compared with trabectedin, ifosfamide, or gemcitabine when used in combination with docetaxel.

There is a dearth of information regarding the costeffectiveness of other systemic agents to treat aSTS in the UK. Soini and colleagues [40] evaluated the cost-effectiveness of trabectedin versus end-stage treatment in Finland and reported ICERs ranging from $€ 42,633$ to $€ 47,735 / \mathrm{QALY}$ depending on the utility values used in the model. A NICE 


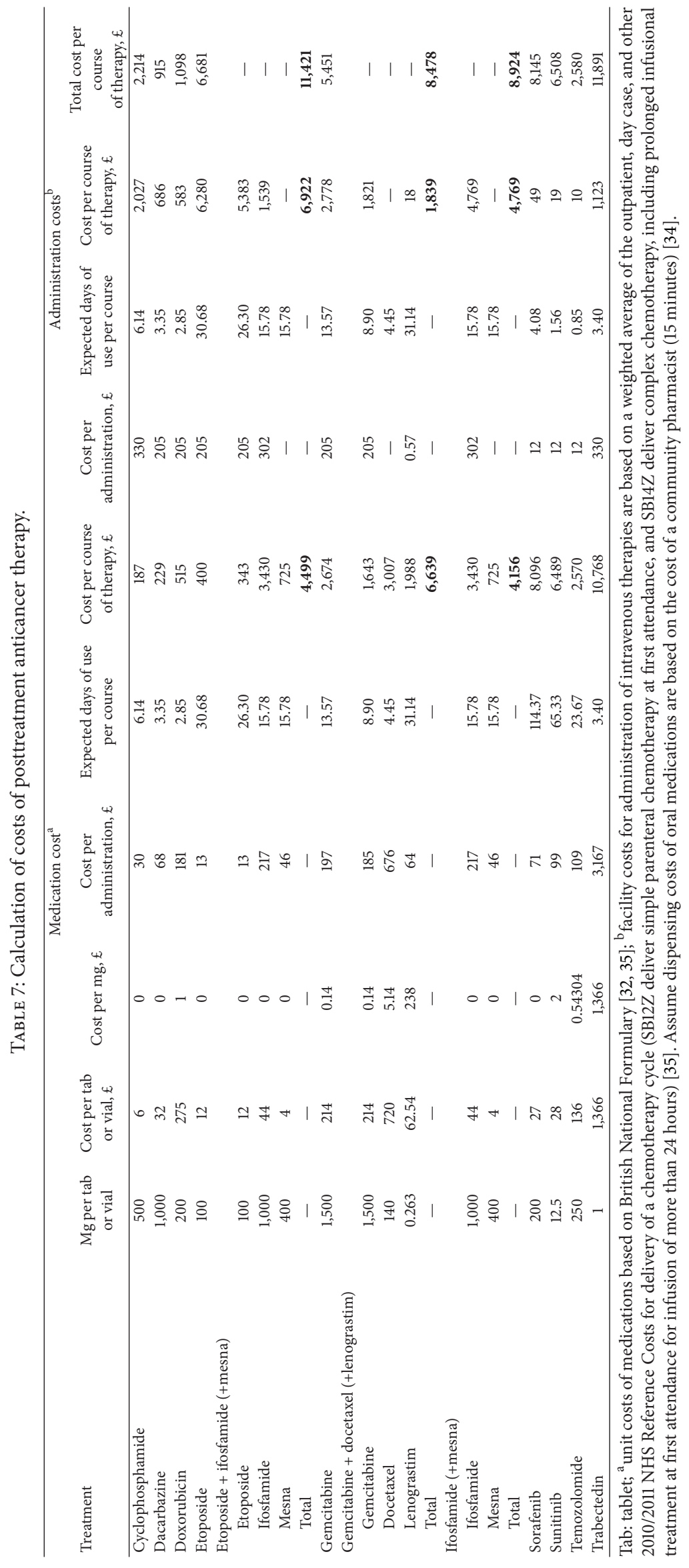




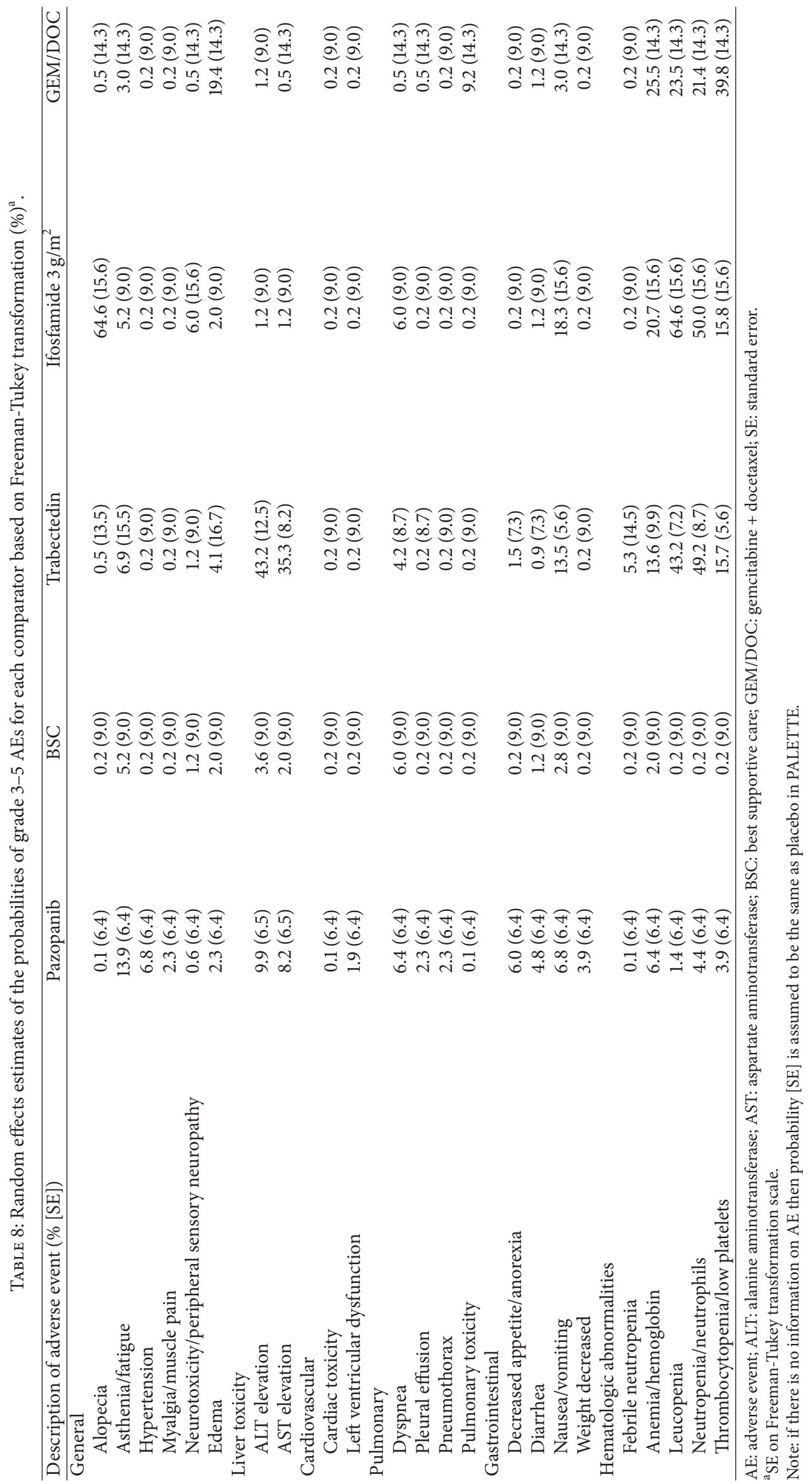


TABLE 9: Costs of adverse events.

\begin{tabular}{|c|c|c|c|c|c|c|}
\hline \multirow{2}{*}{$\mathrm{AE}$} & \multicolumn{2}{|c|}{ Probability that $\mathrm{AE}$ is serious } & \multicolumn{2}{|c|}{ Cost per $\mathrm{AE}, £$} & \multicolumn{2}{|c|}{ Weighted average cost per $\mathrm{AE}, £$} \\
\hline & Pazopanib & Placebo & Nonserious & Serious & Pazopanib & Placebo \\
\hline \multicolumn{7}{|l|}{ General } \\
\hline Alopecia & 100 & 0 & 0 & 0 & 0 & 0 \\
\hline Asthenia/fatigue & 15 & 17 & 122 & 122 & 122 & 122 \\
\hline Hypertension & 0 & 0 & 122 & 2,234 & 122 & 122 \\
\hline Myalgia/muscle pain & 40 & 0 & 122 & 122 & 122 & 122 \\
\hline Neurotoxicity/peripheral sensory neuropathy & 100 & 100 & 122 & 1,320 & 1,320 & 1,320 \\
\hline Edema & 0 & 0 & 122 & 1,602 & 122 & 122 \\
\hline \multicolumn{7}{|l|}{ Liver toxicity } \\
\hline ALT elevation & 100 & 0 & 122 & 2,664 & 2,664 & 122 \\
\hline AST elevation & 100 & 100 & 122 & 2,664 & 2,664 & 2,664 \\
\hline \multicolumn{7}{|l|}{ Cardiovascular } \\
\hline Cardiac toxicity & 100 & 0 & 122 & 3,843 & 3,843 & 122 \\
\hline Left ventricular dysfunction & 100 & 0 & 122 & 3,843 & 3,843 & 122 \\
\hline \multicolumn{7}{|l|}{ Pulmonary } \\
\hline Dyspnea & 75 & 0 & 122 & 878 & 689 & 122 \\
\hline Pleural effusion & 0 & 0 & 122 & 1,974 & 122 & 122 \\
\hline Pneumothorax & 100 & 25 & 122 & 1,974 & 1,974 & 585 \\
\hline Pulmonary toxicity & 100 & 0 & 122 & 1,713 & 1,713 & 122 \\
\hline \multicolumn{7}{|l|}{ Gastrointestinal } \\
\hline Decreased appetite/anorexia & 60 & 0 & 122 & 122 & 122 & 122 \\
\hline Diarrhea & 0 & 0 & 122 & 1,171 & 122 & 122 \\
\hline Nausea/vomiting & 7 & 0 & 122 & 1,171 & 195 & 122 \\
\hline Weight decreased & 9 & 0 & 122 & 122 & 122 & 122 \\
\hline \multicolumn{7}{|l|}{ Hematologic abnormalities } \\
\hline Febrile neutropenia & 100 & 67 & 122 & 4,417 & 4,417 & 2,999 \\
\hline Anemia/hemoglobin & 0 & 0 & 122 & 1,482 & 122 & 122 \\
\hline Leucopenia & 0 & 0 & 122 & 4,417 & 122 & 122 \\
\hline Neutropenia/neutrophils & 100 & 100 & 122 & 4,417 & 4,417 & 4,417 \\
\hline Thrombocytopenia/low platelets & 50 & 50 & 122 & 2,051 & 1,086 & 1,086 \\
\hline
\end{tabular}

AE: adverse event; ALT: alanine aminotransferase; AST: aspartate aminotransferase.

evaluation of trabectedin versus end-stage treatment based on the same model reported an ICER of $£ 56,985 /$ QALY [41]. However, criticism of this model [42] has suggested that the incremental mean survival benefit of 21.1 months for trabectedin versus 7.2 months for end-stage treatment is clinically implausible and might be overestimated.

In the PALETTE study, there was a 3-month gain in PFS for pazopanib compared with BSC [12]. However, an imbalance in the use of PTACT between the two treatment arms may have affected the translation of the PFS benefit to OS. Of the $94 \%$ of patients who were off-protocol at the data cutoff date, $62 \%$ of patients in the placebo group and $45 \%$ of patients in the pazopanib group received additional chemotherapy, and $14 \%$ of patients in the placebo group versus $10 \%$ in the pazopanib group received targeted therapies. Given limitations in the data available from the PALETTE trial, it was infeasible to reliably adjust for differences in PTACT use. Therefore, we used OS data as observed and included the estimated costs of PTACT in each group. While this approach is internally consistent with respect to estimates of effectiveness and costs, it may not be generalizable to other settings, where treatment with placebo followed by PTACT is not a widely used treatment strategy.

While the PALETTE trial provided relatively robust information on utility values during PFS for patients treated with pazopanib and BSC, there was relatively little information on utility values after disease progression. Data from the PALETTE trial were combined with data from a vignettes study to estimate utility values for the PPS state $[13,23]$. The model was relatively sensitive to the assumed decrement in utility following progression. Although utilities from vignettes studies have been used in numerous prior costeffectiveness analyses of oncology therapies, the validity of the values obtained from such studies has never been formally assessed.

It is debatable whether placebo represents an appropriate treatment strategy given that the majority of patients in PALETTE went on to receive other active therapies. We therefore conducted a secondary analysis in which we compared pazopanib with other widely used chemotherapies. In this analysis, pazopanib was estimated to be dominant (i.e., provides greater QALYs at a lower cost) compared with trabectedin, ifosfamide, and gemcitabine plus docetaxel. However, the estimated differences in PFS and OS between pazopanib and these treatments were small and based on an unadjusted or naive indirect treatment comparison. Given the small differences and inherent uncertainty associated with these comparisons, no firm conclusion can be drawn with respect to the relative cost-effectiveness of pazopanib versus these treatments. 
There may be other important factors besides costeffectiveness that should be considered in reimbursement decisions regarding pazopanib in this indication. In particular, STS is an ultra-rare, incurable disease with short life expectancy and for which existing therapies are inadequate. Pazopanib represents a novel therapeutic class for the treatment of this condition. As an oral therapy, pazopanib may be an option for patients who wish to receive treatment at home.

\section{Conclusion}

From a UK healthcare system perspective, taking into account the threshold of $£ 30,000 / Q A L Y$, pazopanib is not cost-effective compared with BSC (base-case); however, pazopanib might be cost-effective compared with trabectedin, ifosfamide, or gemcitabine when used in combination with docetaxel.

\section{Appendix}

\section{Model Inputs and Parameters}

See Tables 7, 8, and 9.

\section{Conflict of Interests}

Jordan Amdahl and Thomas E. Delea are employees of PAI, which has received research funding and consulting fees from GlaxoSmithKline (GSK) for activities related to this study, and received support for travel to meetings to present the study results. Lily Lewis is an employee of the York Health Economics Consortium (YHEC) and served as a consultant to PAI for which YHEC received research funding and consulting fees from PAI for activities related to this study. PAI and YHEC also received consulting fees and research funding from GSK for activities unrelated to this study. Stephanie C. Manson, Robert Isbell, and Jose Diaz are employees of and own stock in GSK, who funded this study. Ayman Chit was an employee of GSK during the conduct of this study and he also owns GSK stock.

\section{Acknowledgments}

Funding for this study was provided to Policy Analysis Inc. by GlaxoSmithKline (GSK). All listed authors meet the criteria for authorship set forth by the International Committee for Medical Journal Editors. The authors wish to acknowledge Nate Connors, Ph.D., and Nancy Price, Ph.D., of AOI Communications, L.P., for medical writing and editorial support (assembling tables and figures, collating author comments, copyediting, fact checking, and referencing) and graphic services, which were funded by GSK.

\section{References}

[1] N. B. Jones, H. Iwenofu, T. Scharschmidt, and W. Kraybill, "Prognostic factors and staging for soft tissue sarcomas: an update," Surgical Oncology Clinics of North America, vol. 21, no. 2, pp. 187-200, 2012.

[2] R. Benjamin, P. W. T. Pisters, L. J. Helman, V. H. C. Bramwell, B. P. Rubin, and B. O'Sullivan, "Sarcomas of soft tissue," in Clinical Oncology, M. D. Abeloff, J. O. Armitage, J. E. Niederhuber et al., Eds., pp. 2009-2056, Churchill Livingstone, Philadelphia, Pa, USA, 2008.

[3] Cancer Research UK, "Soft tissue sarcoma incidence statistics," http://www.cancerresearchuk.org/cancer-info/cancerstats/ types/soft-tissue-sarcoma/incidence/.

[4] J. M. Coindre, P. Terrier, L. Guillou et al., "Predictive value of grade for metastasis development in the main histologic types of adult soft tissue sarcomas: a study of 1240 patients from the French Federation of Cancer Centers Sarcoma Group," Cancer, vol. 91, no. 10, pp. 1914-1926, 2001.

[5] R. Grimer, I. Judson, D. Peake, and B. Seddon, "Guidelines for the management of soft tissue sarcomas," Sarcoma, vol. 2010, Article ID 506182, 15 pages, 2010.

[6] A. Italiano, S. Mathoulin-Pelissier, A. le Cesne et al., "Trends in survival for patients with metastatic soft-tissue sarcoma," Cancer, vol. 117, no. 5, pp. 1049-1054, 2011.

[7] P. G. Casali, L. Jost, S. Sleijfer, J. Verweij, and J.-Y. Blay, "Soft tissue sarcomas: ESMO clinical recommendations for diagnosis, treatment and follow-up," Annals of Oncology, vol. 20, no. 4, pp. iv132-iv136, 2009.

[8] The ESMO/European Sarcoma Network Working Group, "Soft tissue and visceral sarcomas: ESMO Clinical Practice Guidelines for diagnosis, treatment and follow-up," Annals of Oncology, vol. 23, supplement 7, pp. vii92-vii99, 2012.

[9] M. Leahy, X. G. del Muro, P. Reichardt et al., "Chemotherapy treatment patterns and clinical outcomes in patients with metastatic soft tissue sarcoma. The SArcoma treatment and Burden of Illness in North America and Europe (SABINE) study," Annals of Oncology, vol. 23, no. 10, pp. 2763-2770, 2012.

[10] US Food and Drug Administration, "Votrient (pazopanib) tablets: for treatment of patients with soft tissue sarcoma," FDA Oncologic Drugs Advisory Committee Briefing Document (NDA 22-465), 2012.

[11] Votrient Summary of Product Characteristics, 2012, http://www .ema.europa.eu/docs/en_GB/document_library/EPAR_-_Product_Information/human/001141/WC500094272.pdf.

[12] W. T. van der Graaf, J. Y. Blay, S. P. Chawla et al., "Pazopanib for metastatic soft-tissue sarcoma (PALETTE): a randomized, double-blind, placebo-controlled phase 3 trial," The Lancet, vol. 379, no. 9829, pp. 1879-1886, 2012.

[13] GlaxoSmithKline, "A randomised double blind phase III trial of pazopanib versus placebo in patients with soft tissue sarcoma whose disease has progressed during or following prior therapy," http://www.gsk-clinicalstudyregister.com/stud -y/VEG110727\#rs.

[14] T. E. Delea, P. Tappenden, O. Sofrygin et al., "Cost-effectiveness of lapatinib plus capecitabine in women with HER2+ metastatic breast cancer who have received prior therapy with trastuzumab," The European Journal of Health Economics, vol. 13, no. 5, pp. 589-603, 2012.

[15] T. E. Delea, K. el Ouagari, J. Rotter, A. Wang, S. Kaura, and G. J. Morgan, "Cost-effectiveness of zoledronic acid compared with clodronate in multiple myeloma," Current Oncology, vol. 19, no. 6, pp. e392-e403, 2012. 
[16] T. E. Delea, J. Amdahl, A. Chit, and M. M. Amonkar, "Costeffectiveness of lapatinib plus letrozole in HER2-positive, hormone receptor-positive metastatic breast cancer in Canada," Current Oncology, vol. 20, no. 5, pp. e371-e387, 2013.

[17] National Institute for Health and Care Excellence (NICE), "Guide to the methods of technology appraisal," 2013, http:// publications.nice.org.uk/guide-to-the-methods-of-technology-appraisal-2013-pmg9/the-reference-case.

[18] S. Sharma, S. Takyar, S. C. Manson, S. Powell, and N. Penel, "Efficacy and safety of pharmacological interventions in secondor later-line treatment of patients with advanced soft tissue sarcoma: a systematic review," BMC Cancer, vol. 13, article 385, 2013.

[19] J. D. Kalbfleisch and R. L. Prentice, The Statistical Analysis of Failure Time Data, Wiley, New York, NY, USA, 1980.

[20] J. F. Tierney, L. A. Stewart, D. Ghersi, S. Burdett, and M. R. Sydes, "Practical methods for incorporating summary time-toevent data into meta-analysis," Trials, vol. 8, article 16, 2007.

[21] J. Amdahl, S. C. Manson, R. Isbell, A. Chit, and T. E. Delea, "Utility mapping of the EORTC QLQ-C30 onto EQ-5D in patients with soft tissue sarcoma," Value in Health, vol. 16, no. 7, p. A419, 2013.

[22] J. M. Giesinger, L. M. Wintner, A. S. Oberguggenberger et al., "Quality of life trajectory in patients with advanced cancer during the last year of life," Journal of Palliative Medicine, vol. 14, no. 8, pp. 904-912, 2011.

[23] B. Mayrbäurl, L. M. Wintner, J. M. Giesinger et al., "Chemotherapy line-associated differences in quality of life in patients with advanced cancer," Supportive Care in Cancer, vol. 20, no. 10, pp. 2399-2405, 2012.

[24] M. A. Elmqvist, M. S. Jordhøy, K. Bjordal, S. Kaasa, and M. Jannert, "Health-related quality of life during the last three months of life in patients with advanced cancer," Supportive Care in Cancer, vol. 17, no. 2, pp. 191-198, 2009.

[25] S. S. Hwang, V. T. Chang, D. L. Fairclough, J. Cogswell, and B. Kasimis, "Longitudinal quality of life in advanced cancer patients: pilot study results from a VA Medical Cancer Center," Journal of Pain and Symptom Management, vol. 25, no. 3, pp. 225-235, 2003.

[26] S. L. Shingler, P. Swinburn, A. Lloyd et al., "Elicitation of health state utilities in soft tissue sarcoma," Quality of Life Research, vol. 22, no. 7, pp. 1697-1706, 2013.

[27] B. Nafees, M. Stafford, S. Gavriel, S. Bhalla, and J. Watkins, "Health state utilities for non small cell lung cancer," Health and Quality of Life Outcomes, vol. 6, article 84, 2008.

[28] P. Swinburn, A. Lloyd, P. Nathan, T. K. Choueiri, D. Cella, and M. P. Neary, "Elicitation of health state utilities in metastatic renal cell carcinoma," Current Medical Research and Opinion, vol. 26, no. 5, pp. 1091-1096, 2010.

[29] NHS National Institute for Health and Care Excellence (NICE), "Pazopanib for the first-line treatment of advanced renal cell carcinoma," National Institute for Health and Care Excellence (NICE) Technology appraisal guidance 215, http://www.nice .org.uk/nicemedia/live/13346/53304/53304.pdf.

[30] National Institute for Health and Care Excellence (NICE), "Tabectedin patient access scheme submission," Technology Appraisals, National Institute for Health and Care Excellence (NICE), PharmaMar, 2009.

[31] T. A. Young, "Estimating mean total costs in the presence of censoring: a comparative assessment of methods," PharmacoEconomics, vol. 23, no. 12, pp. 1229-1242, 2005.
[32] British National Formulary (BNF) 63, British Medical Journal Publishing Group and Pharmaceutical Press, 2012.

[33] P. Pautier, A. Floquet, N. Penel et al., "Randomized multicenter and stratified phase II study of gemcitabine alone versus gemcitabine and docetaxel in patients with metastatic or relapsed leiomyosarcomas: a Fédération Nationale des Centres de Lutte Contre le Cancer (FNCLCC) French Sarcoma Group Study (TAXOGEM study)," The Oncologist, vol. 17, no. 9, pp. 1213-1220, 2012.

[34] L. Curtis, Unit Costs of Health and Social Care 2010, University of Kent, 2010.

[35] NHS Reference Costs 2010-2011, "NHS trust and PCT combined reference cost schedules," 2012, http://www.dh.gov .uk/en/Publicationsandstatistics/Publications/PublicationsPolicyAndGuidance/DH_131140.

[36] I. Judson, O. al-Muderis, D. Scott, A. Lloyd, F. Alonso, and B. Garcia, "Cost of management of metastatic soft tissue sarcoma," in Proceedings of the National Cancer Research Institute (NCRI) Cancer Conference, NCRI, Birmingham, UK, October 2007.

[37] A. H. Briggs, "Handling uncertainty in cost-effectiveness models," PharmacoEconomics, vol. 17, no. 5, pp. 479-500, 2000.

[38] M. Lothgren and N. Zethraeus, "Definition, interpretation and calculation of cost-effectiveness acceptability curves," Health Economics, vol. 9, no. 7, pp. 623-630, 2000.

[39] M. D. Rawlins and A. J. Culyer, "National institute for clinical excellence and its value judgments," British Medical Journal, vol. 329, no. 7459, pp. 224-227, 2004.

[40] E. J. O. Soini, B. G. san Andrés, and T. Joensuu, "Trabectedin in the treatment of metastatic soft tissue sarcoma: costeffectiveness, cost-utility and value of information," Annals of Oncology, vol. 22, no. 1, pp. 215-223, 2011.

[41] C. Blomqvist, R. Johansson, and M. Tarkkanen, "Trabectedin in the treatment of metastatic soft-tissue sarcoma: costeffectiveness and cost-utility are yet to be proved," Annals of Oncology, vol. 22, no. 4, p. 988, 2011.

[42] NHS National Institute for Health and Clinical Excellence (NICE), "Trabectedin for the treatment of advanced soft tissue sarcoma," http://www.nice.org.uk/nicemedia/live/12813/47472/ 47472.pdf.

[43] A. T. van Oosterom, H. T. Mouridsen, O. S. Nielsen et al., "Results of randomised studies of the EORTC Soft Tissue and Bone Sarcoma Group (STBSG) with two different ifosfamide regimens in first- and second-line chemotherapy in advanced soft tissue sarcoma patients," European Journal of Cancer, vol. 38, no. 18, pp. 2397-2406, 2002.

[44] G. D. Demetri, S. P. Chawla, M. von Mehren et al., "Efficacy and safety of trabectedin in patients with advanced or metastatic liposarcoma or leiomyosarcoma after failure of prior anthracyclines and ifosfamide: results of a randomized phase II study of two different schedules," Journal of Clinical Oncology, vol. 27, no. 25, pp. 4188-4196, 2009.

[45] R. Garcia-Carbonero, J. G. Supko, R. G. Maki et al., "Ecteinascidin-743 (ET-743) for chemotherapy-naive patients with advanced soft tissue sarcomas: multicenter phase II and pharmacokinetic study," Journal of Clinical Oncology, vol. 23, no. 24, pp. 5484-5492, 2005.

[46] A. le Cesne, J. Y. Blay, I. Judson et al., "Phase II study of ET-743 in advanced soft tissue sarcomas: a European Organisation for the Research and Treatment of Cancer (EORTC) Soft Tissue and Bone Sarcoma Group trial," Journal of Clinical Oncology, vol. 23, no. 3, pp. 576-584, 2005. 
[47] A. Yovine, M. Riofrio, J. Y. Blay et al., "Phase II study of ecteinascidin-743 in advanced pretreated soft tissue sarcoma patients," Journal of Clinical Oncology, vol. 22, no. 5, pp. 890899, 2004.

[48] M. L. Hensley, J. A. Blessing, K. DeGeest, O. Abulafia, P. G. Rose, and H. D. Homesley, "Fixed-dose rate gemcitabine plus docetaxel as second-line therapy for metastatic uterine leiomyosarcoma: a Gynecologic Oncology Group phase II study," Gynecologic Oncology, vol. 109, no. 3, pp. 323-328, 2008. 


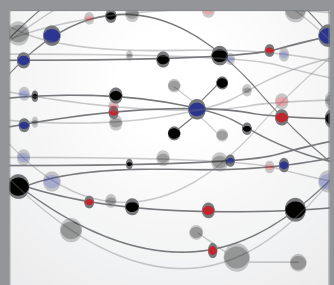

The Scientific World Journal
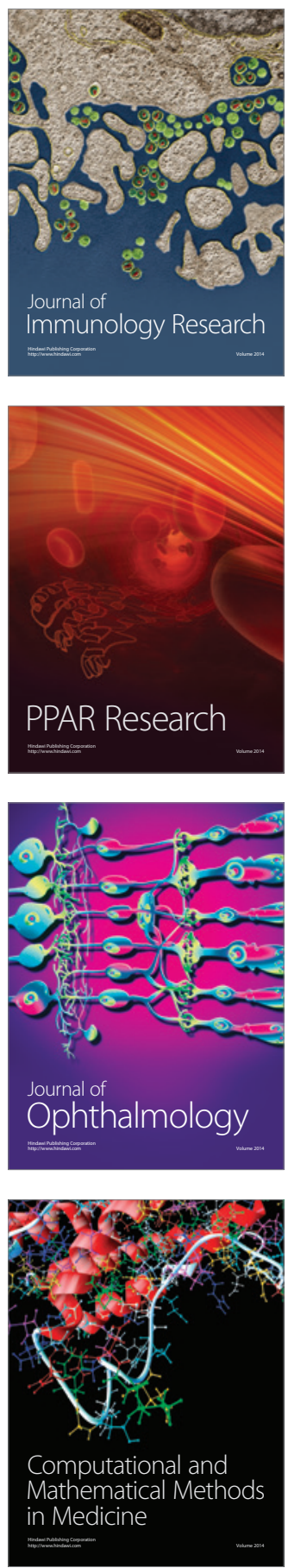

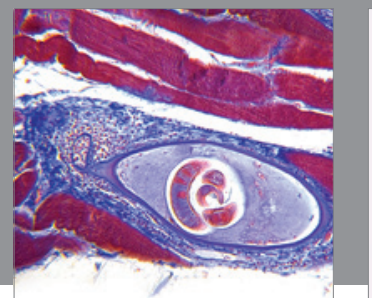

Gastroenterology

Research and Practice
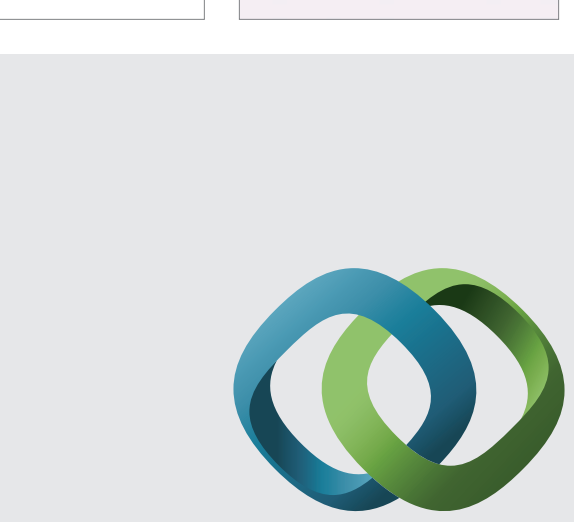

\section{Hindawi}

Submit your manuscripts at

http://www.hindawi.com
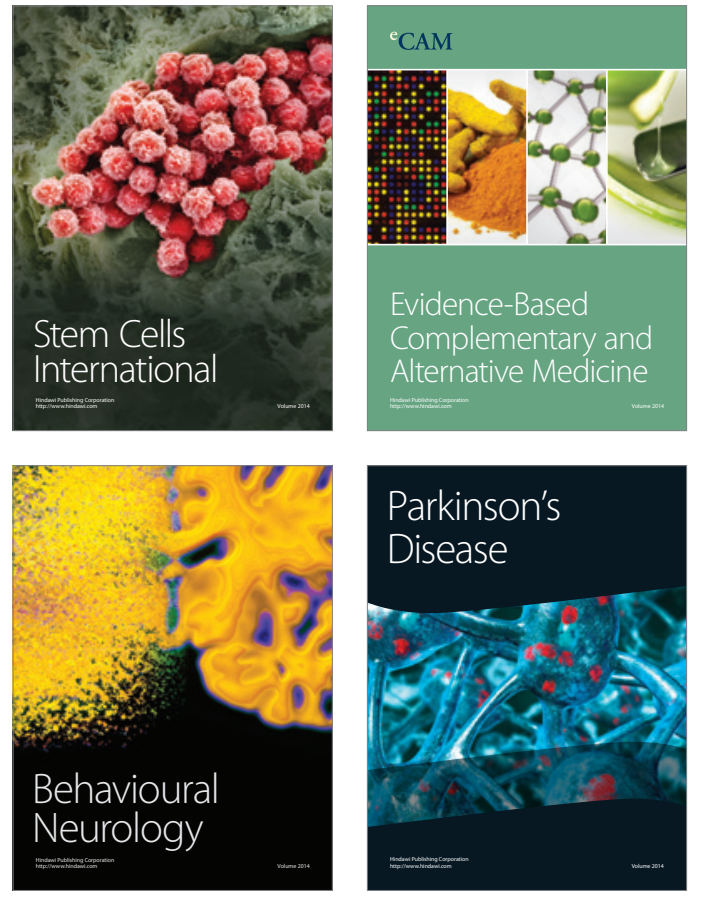
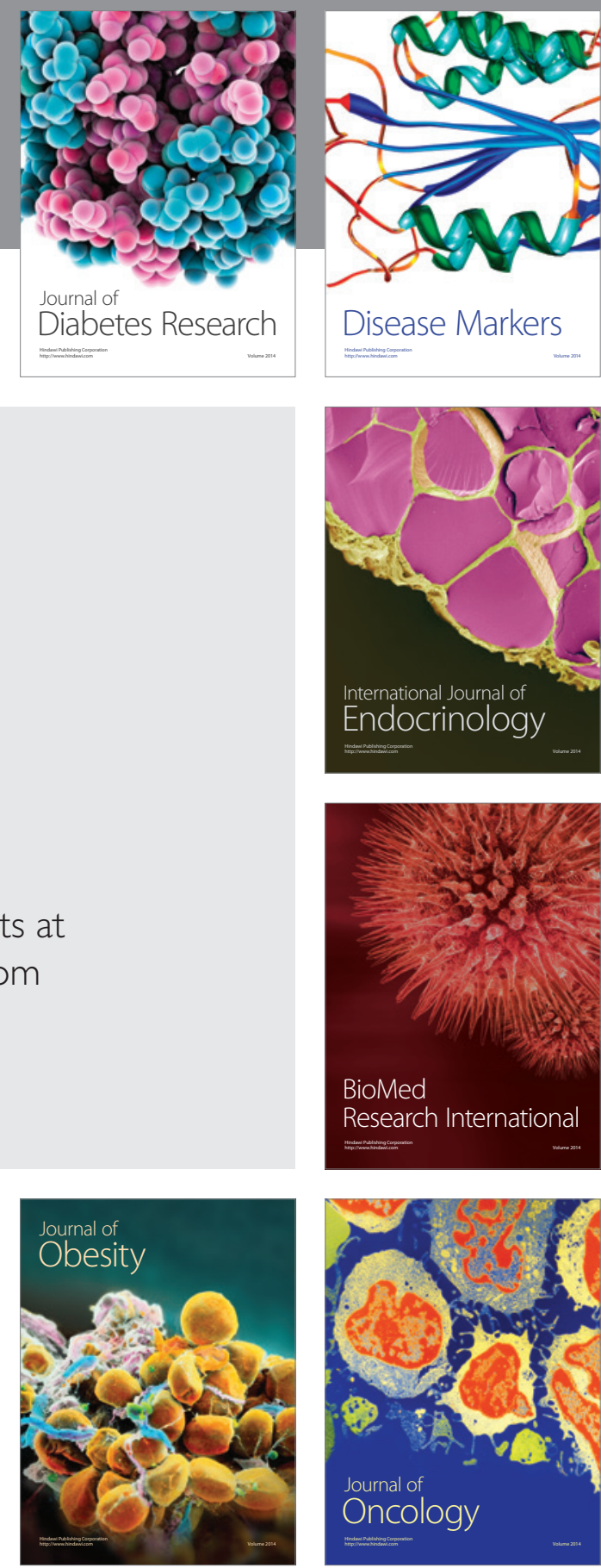

Disease Markers
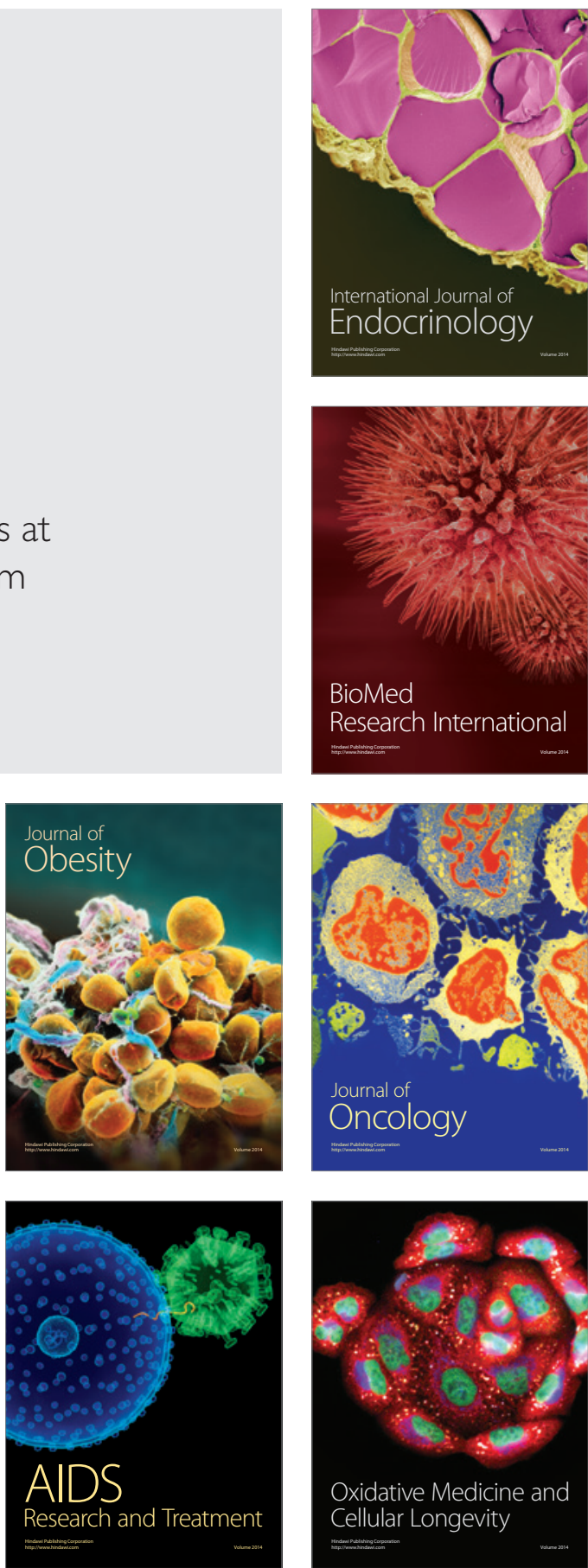